\title{
Glutaminase Inhibitor CB-839
}

National Cancer Institute

\section{Source}

National Cancer Institute. Glutaminase Inhibitor CB-839. NCI Thesaurus. Code C114381.

An orally bioavailable inhibitor of glutaminase, with potential antineoplastic activity. Upon oral administration, CB-839 selectively and irreversibly inhibits glutaminase, a mitochondrial enzyme that is essential for the conversion of the amino acid glutamine into g lutamate. By blocking glutamine utilization, proliferation in rapidly growing cells is impaired. Glutamine-dependent tumors rely on the conversion of exogenous glutamine into g lutamate and glutamate metabolites to both provide energy and generate building blocks for the production of macromolecules, which are needed for cellular growth and survival. 